\title{
A LEGITIMIDADE DE NORMAS INTERNACIONAIS NA TEORIA PURA DO DIREITO ${ }^{1}$
}

\author{
Felipe Kern Moreira²
}

Sumário: 1 Introdução. 2 A questão da legitimidade na Teoria Pura do Direito. $3 \mathrm{~A}$ norma fundamental: resposta à questão da legitimidade? 3.1 Ideias de legitimidade aplicadas à norma fundamental. 3.1.1 Fundamento de existência: consenso e consentimento. 3.1.2 Atração gravitacional em direção ao cumprimento: quatro critérios. 4 Considerações Finais: por que não valores? Referências.

Resumo: O artigo propõe que a norma fundamental exerça, na teoria pura do direito, uma função de fundamento de legitimidade. A metodologia do artigo centra-se na análise das principais obras que descrevem e informam a Teoria Pura do Direito. Noções teóricas de legitimidade são aplicadas à norma fundamental a fim de dar a conhecer as características da legitimidade de normas de direito internacional.

Palavras-chave: legitimidade, norma fundamental, Hans Kelsen, direito internacional.

\begin{abstract}
This article proposes that the basic norm exercises, in the pure theory of law, a function of the basis of legitimacy. The methodology of this article focuses on the analysis of the major works that describe and inform the Pure Theory of Law. Theoretical notions of legitimacy are applied to the basic norm in order to make known the features of the international law's legitimacy.
\end{abstract}

Key-words: legitimacy, basic norm, Hans Kelsen, international law.

\section{INTRODUÇÃO}

Este artigo propõe que a norma fundamental exerce, na teoria pura do direito, a função de fundamento estático de legitimidade de normas internacionais. As noções de legitimidade utilizadas para tal análise não se limitam às de Hans Kelsen. Isto não significa que a norma fundamental seja causa eficiente para gerar comportamento social de atores internacionais. A norma fundamental explica, somente em parte, a atração gravitacional em direção ao cumprimento de normas, num ambiente societário não coercitivo.

A metodologia do artigo centra-se na análise das principais obras que descrevem e informam a Teoria Pura do Direito, segundo o conceito de legitimidade de uma ordem jurídica, o que deságua, inevitavelmente, na questão da norma fundamental na teoria das normas de Hans Kelsen. Tomando em conta o tom abstrato característico da linguagem teórico-jurídica, trata-se legitimidade do eixo

\footnotetext{
${ }^{1}$ Esta pesquisa obteve apoio financeiro do CNPq e do DAAD.

${ }^{2}$ Bacharel em Ciências Jurídicas pela FURG (2001), Mestre (2005) e Doutor (2009) em Relações Internacionais pela UnB. Professor Adjunto do Curso de Bacharelado em Relações Internacionais e do Programa Multidisciplinar de Mestrado em Sociedade e Fronteira, da Universidade Federal de Roraima-UFRR.
} 
entre o direito e diversas outras dimensões da vida que expressam os aspectos viscerais das sociedades: poder, capital, cultura, ideias, transformação.

É possível descrever o que seja legitimidade no direito internacional sem ter que recorrer a elementos transcendentes ao sistema jurídico. Essa descrição pode responder à pergunta sobre qual o lugar do elemento legitimidade na Teoria Pura do Direito. E o lugar da legitimidade na Teoria Pura é o mesmo da norma fundamental, não obstante os fatores que explicam a geração de comportamento de Estados, conforme normas de direito internacional ajam além de um fator estático.

\section{A QUESTÃO DA LEGITIMIDADE NA TEORIA PURA DO DIREITO}

O texto, de 1911, sobre 'As fronteiras do método jurídico e sociológico', permite verificar que Hans Kelsen compreendia que a ficção necessária - a qual respondia a pergunta sobre o fundamento de validade de normas jurídicas - possuía um papel de legitimação e, ainda mais, que esta legitimação é o porquê de normas serem respeitadas. Aqui, o que Kelsen denomina ato psíquico-real de reconhecimento de normas válidas dirige-se à obtenção de legitimação. E legitimação - para o jovem Kelsen - é a explicação da obediência às normas3.

O termo legitimidade é citado na primeira edição da Teoria Pura do Direito de 1934 de forma a confirmar que Hans Kelsen compreendia a norma fundamental enquanto fator de legitimidade do ordenamento jurídico. Por outro lado, o conceito de legitimidade nesta obra não obedece a um rigorismo conceitual.

No capítulo V, da Teoria Pura do Direito, de 1934, que trata da ordem jurídica e seu escalonamento, mais propriamente no subcapítulo 30, intitulado 'A norma fundamental do ordenamento jurídico estatal', a letra 'c' trata, particularmente, do 'Direito Internacional e a norma fundamental das ordens jurídicas estatais'. Neste tópico é escrito que a partir da proposição de que a validade tem uma conhecida eficácia, a saber, uma conhecida relação de correspondência em relação ao condicionamento de um ordenamento jurídico, desta forma, a validade é expressa somente pelo conteúdo de uma norma jurídica positiva, não do ordenamento estatal, mas sim do direito internacional.

\footnotetext{
$3^{\prime \prime}(\ldots)$ la moderna teoria del reconocimiento le ofrece a una pregunta normativa, o sea, dirigida a obtener una legitimación, solamente una respuesta que brinda una explicación del hecho real, es decir, una respuesta explicativa. Pero? Que és lo que se gana con este ato psíquico-real del reconocimiento? Evidentemente sólo una explicación de la validez de ser de las normas, es decir, una explicación de por que los hombres respetan en realidad las normas.” (KELSEN apud CORREAS, 1989, 293)
} 
Esta norma positiva de direito internacional, para Kelsen, legitima o efetivo poder estabelecido e delega, assim, o que esta ordem coatora abarca (KELSEN, 2008, 81). Esta utilização do termo legitimidade indica que para Kelsen a conceituação possui um viés político e jurídico. A norma fundamental de direito internacional legitima o poder capaz de estabelecer uma ordem jurídica vinculante e eficaz. A natureza legitimadora da norma fundamental de direito internacional possui duas características passíveis de reconhecimento: gerar comportamento e suportar um ordenamento jurídico.

Outra utilização da terminologia legitimidade na versão de 1934 dá-se no contexto da própria construção teórica, quando Kelsen não aceita que a teoria pura possa legitimar o Estado pelo direito. Argumenta que isto é impossível em, pelo menos, dois sentidos. A teoria nega que a ciência jurídica possibilite a justificativa do sistema jurídico dos Estados através do direito e nega também que isto possa acontecer através da ciência jurídica mesma. Esta justificativa significa valoração, e valorar - que é uma ação subjetiva - é tarefa da ética e da política e não do conhecimento objetivo (KELSEN, 2008, 137).

Essas preocupações da teoria pura no campo teórico permitem reunir elementos para compreender o que seja legitimidade e encontram-se no capítulo VIII da versão de 1934 que trata da relação entre direito e Estado. O Estado é uma ordem jurídica, mas nem toda ordem jurídica se designa como Estado. O Estado denominase como ordem jurídica quando esta alcança um reconhecido grau de centralização (KELSEN, 2008, 127-128).

Em síntese, aqui é possível encontrar um significado de legitimidade enquanto justificação (Rechtsfertigung) de um sistema jurídico. Esta interpretação é possível ser compreendida a partir do tema do capítulo VIII (Direito e Estado). Em dois momentos, na edição de 1934, o termo legitimidade é mencionado. O primeiro é na função da norma fundamental internacional: legitimar o poder e delegar o que a ordem abarca. O segundo é negar à teoria em si ou ao direito o papel de legitimação do Estado. Estes usos não impedem que a norma fundamental legitime o ordenamento internacional. Inclusive, reforçam esta interpretação.

Na 'Teoria Geral do Direito e do Estado', de 1945, ao tema da legitimidade são dedicadas reflexões mais precisas. A própria localização do tópico intitulado 'princípio da legitimidade' oferece informações importantes para a compreensão da gradual importância que o tema assumiria no positivismo normativo de Kelsen. A 
seção sobre 'o direito enquanto um sistema dinâmico de normas' é sucedido pelo título 'a norma fundamental de um ordenamento jurídico', a qual é dividida em subtópicos denominados 'a norma fundamental e a Constituição', 'a função específica da norma fundamental' e, então, 'o princípio da legitimidade'.

A obra em referência, no contexto da opção metodológica de divisão dos temas, sugere que a questão da legitimidade possua relação com a norma fundamental. Kelsen afirma que a norma fundamental não introduz nas ciências jurídicas nenhum método novo e, sim, meramente, explicita o que todos os juristas assumem quando eles consideram que o direito positivo atua num sistema de normas válidas e que esta validade não provém do direito natural (KELSEN, 1949, 116).

Antes da formulação do que denomina o 'princípio da legitimidade', Kelsen formula uma pergunta: como são possíveis as afirmações dos juristas acerca de normas legais, deveres legais, direitos legais e daí por diante? Esta pergunta diz respeito à constatação acerca da existência da norma fundamental. $\mathrm{O}$ fato de a norma fundamental existir, no que ele denomina 'consciência jurídica', é o resultado da análise das afirmações jurídicas (KELSEN, 1949, 117). Segue a formulação do princípio:

\footnotetext{
The validity of legal norms may be limited in time, and it is important to notice that the end as well as the beginning of this validity is determined only by the order to which they belong. They remain valid as long as they have not been invalidated in the way which the legal order itself determines. This is the principle of legitimacy (KELSEN, 1949, 117).
}

Fica mais evidente na passagem aqui estudada que o que Kelsen entende por princípio da legitimidade não necessariamente reflete o sentido que o conceito assume nas contribuições contemporâneas de teorias políticas e jurídicas. Além disso, a forma como legitimidade será tratada, na 'Teoria Geral do Direito e do Estado', não esgota o conteúdo que o conceito assume ao longo das versões da Teoria Pura do Direito. O conceito de princípio da legitimidade possui a particularidade de ser a primeira menção expressa ao tema legitimidade.

O que dificulta a aplicação do princípio ao plano do direito internacional é que as reflexões que seguem a descrição do princípio indicam que o autor tinha em mente, prevalentemente, o plano constitucional. Afirma que o princípio atua somente sob certas condições já que falha no caso de revoluções, no sentido de um golpe de Estado. Isto porque a revolução, em um sentido amplo, ocorre quando a ordem legal de uma comunidade é anulada e substituída por uma nova ordem de maneira ilegítima, no sentido de não ser prescrita pela primeira ordem a qual sucedeu 
(KELSEN, 1949, 117).

Segundo Carl Schmitt, a noção de princípio da legitimidade enquanto continuidade da ordem política que justifica - ou melhor, legitima o direito - provém do princípio da legitimidade das monarquias dinásticas europeias. Este elemento é bem perceptível nos contextos em que Kelsen explica o princípio da legitimidade nas versões de 1945 e 1961. O princípio conferira legitimidade às intervenções das grandes potências na Europa e também foi aplicado nas intervenções na América Latina em relação às revoluções republicanas. $\mathrm{Na}$ análise de Schmitt no artigo 'Völkerrechtliche Grossraumordnung mit interventionsverbot für raumfremde Mächte', de 1941, a Doutrina Monroe foi um exemplo da contrariedade ao princípio da monarquia dinástica, na medida em que os povos da América não mais seguiriam as potências do além-mar e não seriam mais sujeitos à colonização (SCHMITT, 1991, 282).

Anna Leisner também oferece contribuição aos estudos de legitimidade na perspectiva constitucional sob a ótica da continuidade. A continuidade proporcionada pelo caráter hereditário da linhagem real permaneceu até o século XX, como um fundamento de legitimidade que prevalecia, em algumas situações, sobre a legalidade (LEISNER, 2002, 165). A perspectiva da legitimidade enquanto continuidade sofreu rupturas e aprimoramentos na medida em que as revoluções que substituíram o Estado monárquico exigiam que o poder revolucionário fosse reconhecido também como legítimo no plano constitucional. A questão tornou-se central dentre juristas europeus e, especialmente, dentre os alemães, dadas as transições revolucionárias de Weimar e do III Reich.

Leisner compreende que a teoria pura do direito de Hans Kelsen não apresenta respostas para a questão da continuidade constitucional, ou seja, como e em quais casos a continuidade jurídica transcorre. Considera que tanto a continuidade como a ruptura permitem as mesmas medidas em relação ao esquema de recepção de normas, são igualmente legais e a legitimidade não é questionada (LEISNER, 2002, 39).

Carl Schmitt encontra nessa questão, acima de tudo, a necessidade da continuidade material. Para ele, a definição de legitimidade enquanto reconhecimento da Constituição não é somente um elemento fático, mas sim de medidas jurídicas para garantir a ordem (LEISNER, 2002, 146).

Para Kelsen, é irrelevante no quanto a substituição da ordem legal foi feita 
de forma violenta em relação aos indivíduos que, até então, ocupavam os órgãos competentes legitimados para criar e fazer emendas à ordem legal. Também é irrelevante no quanto a substituição foi feita mediante movimento de massas ou por pessoas que estavam em posições no governo legítimo. Do ponto de vista jurídico, o critério decisivo do reconhecimento da existência de uma revolução é que a ordem vigente é destituída e substituída por uma nova ordem numa forma que a anterior não havia previsto ou antecipado.

A partir da análise do tópico de Kelsen sobre o princípio da legitimidade, observa-se que a expressão legitimidade não mais é usada ao longo de todo o tópico, a não ser para fechar o texto e repetir a nomenclatura do princípio ao reafirmar que uma ordem legal deixaria de ser válida a partir do momento em que, mediante revolução, a antiga ordem fosse destituída do plano da validade. O princípio da legitimidade diz respeito à continuidade do plano da validade de determinada ordem legal:

This shows that all norms of the old order have been deprived of their validity by revolution and not according to the principle of legitimacy. And they have been so deprived not only de fact but also de jure (KELSEN, 1949, 118).

A partir do contexto discursivo e metodológico da obra, pode-se interpretar que o conceito ordem refere-se à ordem legal, já que as considerações em referência encontram-se na primeira parte da obra ('O Direito'), no capítulo X ('Ordem Legal'), que inaugura a segunda parte do capítulo referente à 'nomodinâmica' em contraposição aos nove primeiros capítulos que tratam da 'nomoestática'.

Nas considerações subsequentes, as quais tratam da 'Mudança na Norma Fundamental', permite-se identificar com maior clareza a interferência política na questão do princípio da legitimidade. Kelsen sugere o exemplo hipotético de um grupo de indivíduos que pretendem introduzir a forma republicana de governo num Estado monárquico. A forma como o caso hipotético é descrito favorece concluir que o conceito de 'ordem' para Kelsen, embora esteja no contexto da ordem legal, ultrapassa a necessidade de uma lei positiva e válida.

If they succeed, if the old order ceases, and the new order begins to be efficacious, because the individuals whose behavior the new order regulates actually behave, by and large, in conformity with the new order, then this order is considered as a valid order. It is now according to this new order that the actual behavior of individuals is interpreted as legal or illegal. But this means that a new basic norm is presupposed. It is no longer the norm according to which the old monarchical constitution is valid, but a norm according to which the new republican constitution is valid, a norm endowing the revolutionary government with legal authority (KELSEN, 1949, 118). 
A passagem lida em conjunto com o princípio da legitimidade faz perceber que uma ordem legal legítima pode ser pressuposta. Permite também conceber que determinado comportamento possa ser considerado lícito ou não em função de uma mudança na ordem política ainda que não completamente transferida para ordem jurídica. A ordem legal - em Kelsen -, concebida como uma ordem constitucional, admite a possibilidade de uma legitimação do sistema legal no plano político.

Kelsen claramente possui a intenção de utilizar os conceitos de validade e de legalidade como distintos de legitimidade. Por validade, a teoria das normas compreende que é pressuposta a sua existência ou pressupõe-se que ela possui 'força de obrigatoriedade' porque foi emitida por uma autoridade competente (KELSEN, 2005, 43 et 45). Por essa razão, uma norma é válida para todos, mesmo na hipótese de seu descumprimento, caso no qual a norma é ineficaz. Legalidade, por sua vez, diz respeito a uma conduta correspondente a uma norma jurídica válida e, nesta medida, na teoria pura do direito, apenas como legalidade é que a justiça pode fazer parte da ciência do direito (idem, ibidem).

Eugenio Bulygin entende validade na teoria jurídica de Hans Kelsen em dois sentidos: o de pertencimento e o de vinculação (BULYGIN, 2005, 94). Normas jurídicas são válidas se pertencem a determinado ordenamento jurídico. Este pertencimento ao escalonado de normas confere obrigatoriedade às normas. Contudo, o que é facultado à norma fundamental na teoria pura do direito não se restringe à validação.

O conceito de legitimidade, na "Teoria Geral do Direito e do Estado", possui dois elementos que merecem destaque: ordem política eficaz e comportamento de indivíduos. Ordem política eficaz é a ordem de uma revolução bem sucedida que precede a ordem legal. O comportamento dos indivíduos é também relevante porque eles, de uma forma geral, efetivamente, se comportam segundo a nova ordem, o que faz considerá-la uma ordem válida. Logo, validade, que é um conceito jurídico e inequívoco na teoria pura do direito, pode existir num contexto de uma ordem legal pressuposta.

O princípio da legitimidade diz respeito ao fato que, determinada ordem legal, confere validade a normas, permanece válida enquanto não for invalidada no modo pelo qual a ordem legal mesma determina. Isto quer dizer que o conceito de legitimidade, na 'Teoria Geral do Direito e do Estado', é relativo ao modo pelo qual a ordem legal é determinada. As considerações sobre a mudança na norma 
fundamental permitem também concluir que a norma fundamental modifica-se antes de necessariamente haver mudança no direito positivo, a saber na ordem constitucional. Por isso, Kelsen afirma que 'a nova norma fundamental é pressuposta'. Nesta medida pode-se afirmar que a norma fundamental é um fator de legitimidade de uma (nova) ordem legal. Este tipo de informação é essencial para estabelecer a relação entre norma fundamental e legitimidade no direito internacional, já que neste não existe Constituição e possibilidade de revolução nos termos da revolução constitucional.

A 'Théorie Pure du Droit: introduction a la science du droit', de 1953, não menciona o princípio da legitimidade. Existe uma lacuna na menção ao princípio entre as versões de 1945 e 1961. No tópico sobre a norma fundamental da ordem jurídica internacional, o argumento teórico de Kelsen parte do caso de uma revolução que pretende mudar o regime legítimo monárquico para o republicano. Suas conclusões são as mesmas das outras obras anteriores. A opção por não mencionar o princípio da legitimidade retira a versão de 1953 das fontes mais expressivas de análise da questão da legitimidade na teoria pura do direito. Digna de referência é a passagem: "Il y a donc un rapport entre la validité et l'efficacité d'un ordre juridique, la premiére dépendant dans une certaine mesure de la seconde" (KELSEN, 1953, 118). Se a citação é colocada em perspectiva com a da versão de 1961: "o princípio da legitimidade é limitado pelo princípio da efetividade" (KELSEN, 1998, 147), então é possível estabelecer a relação entre validade e legitimidade: a norma primeira é o fundamento de validade de uma ordem jurídica na medida em que a efetividade desse ordenamento normatiza sua legitimidade.

Na segunda edição da Teoria Pura do Direito, concluída em Berkley em 1960, também é possível identificar mudanças em relação à redação do texto de 1945. Os tópicos 'princípio da legitimidade', 'mudança na norma fundamental' e 'princípio da eficácia' constam, no mesmo contexto metodológico e discursivo da 'Teoria Geral do Direito e das Normas', num capítulo denominado 'legitimidade e efetividade'.

A mudança substancial do texto de 1945 para o texto de 1961 é que existe uma maior harmonização da concepção de uma nova ordem válida com a exigência de uma Constituição vigente. Para tal, Kelsen retira do texto referências expressas à ordem política eficaz e ao comportamento dos indivíduos conforme a nova ordem. Esta mudança resta clara na passagem onde cita a possibilidade da revolução não chegar ao termo desejado: 
Se a revolução não fosse bem-sucedida, quer dizer, se a Constituição revolucionária - que não veio à existência de acordo com a antiga Constituição - não se tivesse tornado eficaz, se os órgãos por ela previstos não tivessem ditado quaisquer leis que fossem de fato aplicadas pelos órgãos previstos nestas leis, mas se, pelo contrário, a antiga Constituição tivesse permanecido eficaz, não haveria qualquer motivo para pressupor uma nova norma fundamental no lugar da antiga. $\mathrm{O}$ princípio que aqui surge em aplicação é o chamado princípio da efetividade. O princípio da legitimidade é limitado pelo princípio da efetividade (KELSEN, 1998, 147).

A constatação das diferentes redações de 1945 e 1961 não necessariamente conduz à conclusão de que houve uma mudança no raciocínio. Na versão de 1961, fica mais claro que a nova ordem é instaurada por uma Constituição. Em ambas as versões, Constituição e norma fundamental não se confundem, e legitimidade diz respeito à possibilidade de modificação de uma ordem legal segundo a ordem vigente.

O que não fica claro é se houve ou não mudança no raciocínio quanto à possibilidade da pressuposição de uma nova norma fundamental. Em outras palavras, não é claro se a partir de uma revolução uma nova ordem legal válida se instaura em virtude de uma norma posta (Constituição) ou suposta (ordem eficaz a partir do comportamento geral dos indivíduos). A resposta a esta questão pode modificar a noção kelseniana de legitimidade adotada até então. Quanto ao tema, o que surge de novo na versão de 1961 é a legitimidade limitada pela efetividade de uma nova ordem legal. É neste contexto que Larx Vinx argumenta que Hans Kelsen emprega o termo legitimidade em diferentes sentidos e que esta utilização sugere que a lei possa legitimar o poder (VINX, 2007, 59).

\section{A NORMA FUNDAMENTAL: RESPOSTA À QUESTÃO DA LEGITIMIDADE?}

No artigo "Alienating Justice: On the surplus value of the twelfth camel", Gunter Teubner lança mão do recurso à antiga história que também fora utilizada inúmeras vezes por Jean-Pierre Dupuy e Niklas Luhmann nos seus debates sobre auto-organização, autopoiesis e ao tratar dos paradoxos do direito. Aqui, o mesmo recurso parece ser apropriado.

Conta-se que um Sheik beduíno, velho e rico, escreveu seu testamento e dividiu entre seus três filhos sua fortuna constituída de uma cáfila de camelos. Achmed, o mais velho, foi herdeiro da primeira metade da fortuna. Ali, o segundo filho, ficou com um quarto e, Benjamin, o mais jovem, com um sexto. Quando o pai morreu, infelizmente, somente onze camelos foram deixados. Achmed, é claro, reclamou seis deles e foi imediatamente contestado por seus irmãos. Quando a 
confusão se instaurou eles procuraram o Khadi que então decidiu: 'Eu ofereço a vocês um dos meus camelos. Devolva-me ele, por vontade de Alá, o mais rápido possível. Agora, com doze camelos a divisão era fácil. Achmed pegou seus seis camelos, Ali pegou seu quarto, que são três camelos, e Benjamim pegou sua sexta parte, dois camelos. E é claro, o décimo segundo camelo que havia sido deixado de fora foi rapidamente devolvido ao Khadi (TEUBNER, 2001, 21).

Teubner assinala que no mesmo lugar onde Derrida observa a violência da autofundamentação da lei, em que Kelsen tinha visto a norma fundamental, e Hart, a norma de reconhecimento, está o décimo segundo camelo. Para eles, o décimo segundo camelo representa alguma coisa a mais do que seu papel simbólico na dinâmica do direito. O camelo é a localização da autorreferencialidade do sistema legal que finaliza a performance de deter os paradoxos e liberar a dinâmica jurídica (TEUBNER, 2001, 21).

Teubner compreende a norma fundamental como a autorrefencialidade ou caráter supletivo da teoria jurídica. De fato, a norma fundamental pode ser compreendida como justificação teórica para que o sistema, idealmente, adquira coesão, na sua forma integral. Contudo, tanto Kelsen quanto Hart não apresentaram a norma fundamental e a regra de reconhecimento como um elemento de suplência teórica.

A interpretação de Teubner caracteriza a norma fundamental num esquema do topo para a base. Kelsen fala da norma fundamental enquanto reconhecimento de ordenamento jurídico eficaz, observado nas relações humanas: da base para o topo. Esta concepção base-topo é reforçada na descrição teórica dada à norma fundamental enquanto hipótese. Nesse caso, é a afirmação hipotética acerca da existência de um fato real no plano internacional: relações de comprometimento mútuo.

A norma fundamental na versão de 1979 é contraditória em si mesma em virtude de não corresponder à realidade4. Esta forma de descrição teórica tardia é

\footnotetext{
4 Na versão de 1979 a norma fundamental de um ordenamento jurídico ou moral não é juridicamente positivada e sim puro pensamento. Isto significa uma norma fictícia no sentido de um ato de vontade não real, mas sim ficcional. Kelsen acrescenta que é ficção no sentido da filosofia Vaihingeriana do 'Como se' (als ob), que é delineada é contraditória em relação à realidade e contraditória em si mesma. Assim a suposição de uma norma fundamental de um ordenamento moral religioso ou de uma ordem jurídica contradiz não somente a realidade, porque tal norma não existe no sentido de um ato efetivo da vontade, mas também é contraditória em si própria porque ela representa a autoridade máxima de uma ordem moral ou jurídica (KELSEN, 1979, 206-207).
} 
resultante da influência de um neokantiano: Hans Vaihinger (1852-1933) com a obra 'Philosophie des Als-Ob'. Kelsen chega a afirmar que é ficção no sentido da filosofia vaihingeriana (KELSEN, 1979, 206). Vaihinger postulava que o homem não pode conhecer a realidade do mundo e, como consequência, constrói sistemas de pensamento que assumem a realidade como alcançada. Assim, o homem comporta-se 'como se' ('als-ob') o mundo correspondesse a essa descrição.

$\mathrm{O}$ ordenamento jurídico eficaz para Kelsen refere-se à consciência da obrigatoriedade de normas costumeiras, ou seja, às relações que ocorrem com a ajuda da ficção. Talvez, por isso, Kelsen afirme que a norma fundamental não possa ser explicada sem o recurso da ficção e não justifique o abandono da hipótese. Também Hart, quando falava da norma de reconhecimento, referia-se às relações sociais como o exercício da jurisprudência no sistema common law. Logo, a norma fundamental e a regra de reconhecimento não servem somente de autoreferrencialidade nas teorias jurídicas, é possível dizer que percorrem as direções de topo-base, que é a autorreferencialidade, e também a de base-topo.

Onde Kelsen situou teoricamente a norma fundamental não é tão simplesmente um lugar de autorreferencialidade teórica; é também o lugar em que a legitimidade encontra-se em sua teoria. Sua formulação, na direção base-topo, da observação da eficácia do ordenamento jurídico internacional para a formulação teórica, permite identificá-la como fator de legitimidade no positivismo jurídico. Do topo para a base está a ficção, que é o exercício incontornável de formar uma síntese, uma abstração das relações entre Estados, a fim de possibilitar que uma constatação empírica possa entrar num campo descritivo e argumentativo (aqui, no caso, de uma teoria jurídica).

José Guilherme Merquior argumenta em sua tese "O problema de Legitimidade em Política Internacional", de 1978, que as contribuições contemporâneas para a questão da legitimidade são provenientes da área jurídica e do legado da filosofia política clássica. No primeiro grupo cita as contribuições de Kelsen e Hart e, no segundo, com o qual estivera efetivamente ocupado em sua exposição, cita, dentre muitos outros, Carl Joachim Friederich e Karl Deutsch, tentando costurar as argumentações em torno do que denomina a caracterização empírica da legitimidade do poder. Para Merquior, Hans Kelsen:

(...) renovou a conceituação de legitimidade da norma. Kelsen estendeu-a como uma validade imanente à lei positiva, mas Herbert Hart, talvez o maior filósofo do direito pós-kelseniano, moderou consideravelmente este radicalismo positivista ao 
subscrever a existência de um mínimo de congruência entre a lei e a moralidade, mínimo este baseado em determinados truísmos sobre a condição humana (MERQUIOR apud LAFER, 1993, 54).

As poucas palavras dedicadas a Hans Kelsen servem para Merquior manifestar-se sobre a renovação da conceituação de legitimidade no campo jurídico. Merquior entende que legitimidade para Kelsen é uma validade imanente à lei positiva. Se o que confere validade às normas na teoria pura é, em última análise, a norma fundamental, então, a norma fundamental internacional é o fundamento de legitimidade de normas internacionais.

Retomando-se a formulação da norma fundamental na versão da 'Teoria Geral do Direito e do Estado', de 1945, a validade de tratados remete à regra geral que obriga Estados a se conduzir de acordo com tratados por eles firmados, norma esta manifestada pela expressão pacta sunt servanda (KELSEN, 2005, 524). A norma fundamental não é o pacta sunt servanda, mas sim a regra geral de comportamento conforme a norma consentida. Assim, a interpretação dada por Merquior é que em Kelsen a legitimidade diz respeito à validade imanente da norma positiva. O que existe de imanente em uma norma além da consciência de obrigatoriedade do cumprimento da norma consentida?

Na mesma sintonia weberiana de Merquior, Weyma Lübbe trata do tema da legitimidade e a questão da validade na teoria jurídica de Hans Kelsen. A definição de validade na sociologia não é a mesma do positivismo jurídico. Estas tipologias obedecem a racionalidades diversas. Para Max Weber, a crença na legalidade era uma forma corrente de legitimidade. Para Lübbe, Weber talvez não concordasse com o princípio do reconhecimento, com a pureza metodológica da teoria pura. Para Weber, a crença na legalidade seria hoje em dia mais que um outro tipo de legitimidade, um fenômeno de massas (LÜBBE, 1991, 65).

A acepção de legitimidade enquanto consentimento possibilita identificar que a norma fundamental na teoria pura do direito é o fundamento de legitimidade do ordenamento jurídico internacional. Essa interpretação é reforçada pela falta de uma autoridade política ou jurídica centralizada nas relações internacionais. A partir de tal acepção, sujeitos de direito internacional, em geral, cumprem normas num ambiente jurídico não coercitivo em virtude de regra costumeira que exige que Estados cumpram o que pactuaram de boa fé.

Sobre a menção que Merquior faz a Hart, é difícil precisar no quanto Hart admitiu elementos de moralidade em seu sistema teórico. Assim como em Kelsen, 
Hart nega que em seu sistema não haja lugar para a moralidade conforme afirmavam seus antípodas e dentre eles, em especial, Ronald Dworkin. No Post Scriptum dedica páginas a explicar defensivamente seus sistemas e no quanto seu positivismo analítico pode incluir princípios e valores. No mais, é concorde com Kelsen que há uma diferença clara entre direito e moral. Merquior faz uma referência à Hart. O sistema teórico de Hart é de difícil transposição para o campo do direito internacional. O papel de uma suposta norma de reconhecimento formada a partir do exercício da jurisdição internacional - tribunais - participa em pequena escala da definição de normas válidas de direito internacional.

\subsection{Ideias de legitimidade aplicadas à norma fundamental}

Legitimidade no direito internacional, em termos gerais, é o fator de justificação de normas jurídicas. A justificativa aparece na literatura sob pelo menos três formas: a ideia de fundamento da existência, a ideia de atração gravitacional e a adoção de valores5. A ideia de um momento de força que acontece na intersecção dos campos político e jurídico, passível de ser descrita no plano teórico, corrobora para a interpretação que a norma fundamental enquanto fator de legitimidade não se restringe à autoreferrencialidade teórica.

\subsubsection{Fundamento de existência: consenso e consentimento}

A ideia de fundamento de existência é uma das formas mais evidentes de associar a norma fundamental kelseniana à questão da legitimidade. Nessa concepção, legitimidade pode ser vista tanto da perspectiva do consenso quanto do consentimento. Na perspectiva do consenso, a legitimidade é o fator capaz de gerar o convencimento que determinados padrões de conduta são exigíveis enquanto obrigação jurídica num determinado contexto social. O consenso não é a norma específica, senão a ideia de como se obedece ao que foi tratado:

(...) a norma fundamental é a instauração do fato fundamental da criação jurídica e pode, nestes termos, ser designada como constituição no sentido lógico-jurídico, para a distinguir da Constituição em sentido jurídico-positivo. Ela é o ponto de partida de um processo: do processo da criação do Direito positivo (KELSEN, 1998, 139).

A norma fundamental, na versão de 1961, é um fato de natureza lógica, a

\footnotetext{
5 As ideias jurídicas acerca de legitimidade debatidas neste artigo estão mais detidamente descritas em contribuição anterior, MOREIRA, 2010.
} 
partir da qual um ordenamento jurídico é revestido de legitimidade. Não é a fórmula, pacta sunt servanda, mas sim o que por essa é expresso (KELSEN, 1998, 151).

A legitimidade, enquanto fundamento da existência de normas jurídicas, possui ainda a perspectiva do consentimento. A partir desta acepção, Kelsen observa na conduta de Estados que existem regras globais que são eficazes (KELSEN, 1998, 151). O positivismo jurídico possui um pressuposto epistemológico traduzido em termos de conceito teórico. O pressuposto epistemológico da norma fundamental é admitir que a realidade acerca do mundo possa ser reconhecida. A tradução dessa possibilidade de (re)conhecimento do mundo é traduzida no positivismo jurídico pelo conceito de eficiência, praticamente inalterado desde a versão de 1934 (KELSEN, 2008, 81). Este tipo de noção principiológica de ciência revela a influência tardia de Kant sobre Kelsen, já que um dos pontos centrais da discordância de Kelsen com a filosofia do conhecimento de Kant é a impossibilidade de conhecer o mundo ${ }^{6}$. Esse dado exerce peso na utilização de Vaihinger. O conhecimento objetivo da realidade (social) é um paradoxo sutil da ciência jurídica: em Kelsen, se é possível, a legitimidade é pressuposta (hipótese); se não é possível, a legitimidade é pura ficção.

$\mathrm{Na}$ formulação da norma fundamental, o consentimento dos Estados é percebido nas regras formadas pelo costume (KELSEN, 1998, 151). O costume diferencia-se do 'uso', na medida em que sujeitos de direito internacional devem estar convencidos de que suas ações ou abstenções cumprem um dever ou que eles exercem um direito (KELSEN, 2008, 307). O convencimento do dever ou do direito é algo anterior à formação da norma costumeira, sendo desta um elemento constituinte. Logo, o fundamento da existência de normas válidas não só consensuais, mas também consentidas (que vigoram) na sociedade internacional, na teoria pura do direito é compreendido como norma fundamental. Tanto a norma fundamental quanto a legitimidade não se restringem ao convencimento, mas a um conjunto de fatores interativos como consenso e noção de direito/dever.

A acepção de legitimidade a partir da perspectiva do consenso, aqui

\footnotetext{
6 "De resto a coisa em si desempenha na filosofia de Kant um papel muito questionável. No trabalho mais representativo da sua filosofia, a Kritik der reinen Vernunft, diz ele: "O que possam ser os objetos em si e enquanto isolados de toda a. receptividade dos nossos sentidos, isso permanece para nos completamente incógnito"; e: "O que possam ser as coisas em si não o sei, e também não preciso saber, que nunca uma coisa me aparece senão no seu fenômeno (manifestação)". Nesse caso, também não se pode saber que o homem como coisa em si é livre, que ele tem esta natureza e não qualquer outra, e não se pode, bem assim, fundamentar nesta afirmação a possibilidade da imputação, decisiva para a Ética de Kant." (KELSEN, 1998, 261)
} 
relacionada à formação de normas internacionais pela via do costume possui, contudo, uma diferença substancial da formulação teórica da norma fundamental. Pode-se, neste caso, falar em legitimidade de direito internacional e de normas internacionais isoladamente tomadas, mas a norma fundamental na perspectiva internacional é somente uma. Esta diferença não argumenta no sentido da não identificação entre a norma fundamental e legitimidade, mas sim caracteriza o esgotamento teórico explicativo da norma fundamental. Por isso a norma fundamental pode ser entendida como o fator de legitimidade estático, pois diz respeito ao reconhecimento do ordenamento jurídico internacional expresso no princípio pacta sunt servanda.

\subsubsection{Atração gravitacional em direção ao cumprimento: quatro critérios}

A legitimidade enquanto atração gravitacional em direção ao cumprimento é outra acepção que pode ser tomada para a análise da norma fundamental. Thomas Franck sugere, nesta acepção, que a propriedade telúrica da norma possa ser explicada a partir de quatro fatores: determinação, validação simbólica, coerência e aderência. A vantagem da relação entre as ideias de Kelsen e Franck é que ambos os autores centralizam suas análises na norma jurídica.

Dos quatro fatores apontados por Franck enquanto propriedades da norma internacional, que conferem percepção de legitimidade, nem todos podem ser associados à norma fundamental do positivismo jurídico. Por exemplo, a determinação é uma propriedade direta de normas internacionais tomadas isoladamente e diz respeito à clareza e precisão de seus comandos. Por isso, afasta-se a possibilidade de associar o fator determinação à norma fundamental. $\mathrm{O}$ mesmo acontece com a questão da validação simbólica, a qual diz respeito aos ritos e atos sociais, num condicionamento representativo e simbólico. Nestes termos, pode-se constatar que as características da norma que Franck denomina 'cultural e antropológica (validação simbólica), bem como linguística e literária estrutural (determinação)' (FRANCK, 1988, 725-726) não estabelecem relação direta com a norma fundamental de Kelsen.

Coesão e aderência são consideradas, por Franck, os critérios respectivamente horizontal e vertical. A coerência é característica ligada ao pertencimento a uma comunidade, diz respeito ao consentimento em relação às responsabilidades derivadas de uma responsabilidade mais geral que é a de ser 
membro de uma comunidade. Nesta lógica, Franck afirma que a força gravitacional em direção à obediência é mais forte se a base da obrigação é mais associativa do que meramente contratual (FRANCK, 1990, 186). Essa noção pode ser relacionada à noção de Hans Kelsen, em que a norma fundamental "representa o pressuposto sob o qual normas globalmente eficazes são consideradas como normas jurídicas que vinculam os Estados." (KELSEN, 1998, 151). Coerência confere legitimidade às normas, mas o fundamento da legitimidade é o fator que dá sentido (coerência) a um ato social supostamente jurídico. Só existem normas internacionais se existir uma alteridade (em última instância comunidade) que reconheça estas regras como válidas. A norma fundamental é, segundo o critério da coerência, fundamento da legitimidade. No contexto da coerência, o lugar em que a norma fundamental está não significa o lugar da legitimidade em si, mas sim o de seu fundamento.

Coerência confere percepção de legitimidade na medida em que normas internacionais estão vinculadas às estruturas fundamentais do ordenamento jurídico. Este é um aspecto que pode ser considerado elemento quase estético do direito: coerência normativa enquanto recta ratio factibilium. Neste contexto, a coesão aproxima-se do consenso, pois normas internacionais detêm mais legitimidade se participam com maior intensidade dos propósitos (políticos) da norma:

\footnotetext{
Rules become coherent when they are applied so as to preclude capricious checker boarding. They preclude caprice when they are applied consistently or, if inconsistently applied, when they make distinctions based on underlying general principles that connect with an ascertainable purpose of the rules and with similar distinctions made throughout the rule system. Validated membership in the community accords equal capacity for rights and obligations derived from its legitimate rule system (FRANCK, 1990, 751).
}

A proposta é que normas jurídicas são mais legítimas se aplicadas consistentemente com os princípios e os propósitos destas normas no sistema político. A este respeito, a norma fundamental é a fonte de unidade de uma diversidade de normas contidas num sistema ou ordenamento (KELSEN, 2008, 73). Em termos práticos, se normas atuam no sentido para o qual foram elaboradas e obedecem a princípios amplamente aceitos no sistema jurídico, possuem mais potencial de serem obedecidas. Existe aqui uma acepção de coerência que escapa ao domínio estático da norma fundamental: a consistência na aplicação de direitos e a igualdade jurídica entre Estados pertencem, respectivamente às práticas jurisdicionais e aos princípios de direito internacional.

A norma jurídica detém maior legitimidade na medida em que reforça o acordo no plano horizontal com o contexto das normas do sistema, dos princípios e 
dos consensos legislativos e jurisprudenciais. No plano da jurisprudência, esse raciocínio fica mais convincente; uma decisão jurisprudencial oferece maior percepção de legitimidade o quanto mais estiver de acordo com outras decisões. A norma fundamental, sob o critério da coerência, delimita o alcance dos elementos capazes de conferir consistência em dado sistema jurídico, o que é ainda mais óbvio no contexto constitucional.

O último critério proposto por Franck é o mais evidente na relação entre legitimidade e norma fundamental. O critério vertical da aderência remete à noção de escalonado (Stufenbau) e hierarquia de normas:

We shall refer to this property as adherence, by which is meant the vertical nexus between a primary rule of obligation, which is the system's workhorse, and a hierarchy of secondary rules identifying the sources of rules and establishing normative standards that define how rules are to be made, interpreted, and applied (FRANCK, 1990, 184).

A aderência, enquanto propriedade da norma que confere percepção de legitimidade, é associada ao campo teórico hartniano, ao reconhecimento de normas jurídicas pela norma secundária. No positivismo jurídico de Kelsen este reconhecimento é compreendido como validação. Uma das diferenças cruciais entre Hart e Kelsen reside na explicação deste sistema de validação. Thomas Franck, quando explica aderência, não faz menção à norma fundamental de Kelsen não obstante esta relação possa ser feita a partir do contexto normativo hierárquico com o qual descreve a teoria de Hart: "In Hart's theory, the highest level of obligation could operate only in respect of a rule which is part of a normative hierarchy capped by an ultimate system-validating rule." (FRANCK, 1990, 186). Segundo o critério vertical de Franck, pode ser atribuída à norma fundamental a função de fundamento de legitimidade, pois é o fundamento último de validação de normas jurídicas.

\section{Considerações Finais: por que não valores?}

É necessário fazer referência à acepção de legitimidade na perspectiva dos valores da sociedade. Tal perspectiva encontra ressonância, por exemplo, nas formulações jusnaturalistas e na fundamentação jurídica dos direitos humanos. Aqui, pode-se explorar a relação entre norma fundamental e legitimidade a partir de duas vias.

A primeira, na teoria pura do direito, pela norma fundamental não possui acepção moral ou valorativa. Esta interpretação parece refletir o que Hans Kelsen 
formulou na versão da teoria pura de $1960^{7}$ e na obra 'O problema da justiça' 8 do mesmo ano.

A segunda refere-se às críticas de Verdross em que paz e ordem são valores e que nem mesmo o positivismo jurídico conseguiu ficar imune aos valores suprapositivos (VERDROSS, 1959, 18). A crítica de Verdross interpreta que a edificação fechada do positivismo jurídico abriu a porta para o jusnaturalismo (VERDROSS, 1959, 19). A crítica de Verdross compreende a versão da 'Teoria Pura do Direito' de 1934, 'O que é justiça' de 1956 e 'Teoria Geral do Direito e do Estado', de 1945 e é 'respondida' por Kelsen na versão de 1960. A partir da crítica de Verdross, pode-se concluir que a teoria de Kelsen tem duas interpretações.

Sobre a relação entre norma fundamental e valores, Bindschedler argumenta que, em última análise, a pergunta sobre a norma fundamental do ordenamento jurídico é uma pergunta filosófica sobre a natureza do homem e do mundo. A partir destes pressupostos conclui que a questão da norma fundamental não poderia ser respondida pela razão, pois se encontra na fronteira da ciência (BINDSCHEDLER, 1960, 76). Aqui se retornaria ao lugar onde está o décimo segundo camelo. Experiências semelhantes à relatada por David Kennedy do seu despertar do sonho cosmopolita do direito internacional9.

O que significa dizer que a norma fundamental é um fundamento estático de legitimidade de normas internacionais? Significa que o reconhecimento de que Estados possuem vontade capaz de ser expressa e comunicada é um pressuposto

\footnotetext{
7“Na norma fundamental do Direito internacional também não está contida qualquer afirmação de um valor transcendente ao Direito positivo; nem mesmo do valor paz, que o Direito internacional geral, criado pela via consuetudinária, e o direito internacional particular, criado com base na norma jurídica pactícia, garantem. O Direito internacional e as ordens jurídicas estaduais que - sob a pressuposição do primado daquele - lhe estão subordinadas são válidos ou vigentes não porque ou na medida em que realizam o valor paz. Podem realizar este valor se e na medida em que valem; e valem se se pressupõe a norma fundamental que institui o costume dos Estados como fato gerador de Direito, qualquer que seja o conteúdo que possam ter as normas assim criadas." (KELSEN, 2008, 151).

8“A norma fundamental de uma ordem jurídica positiva não é de forma alguma uma norma de justiça (...) não pode ser - como no direito natural - um critério de apreciação do direito positivo. (...) A norma fundamental definida pela Teoria Pura do Direito não é um direito diferente do direito positivo: ela apenas é o seu fundamento de validade, a condição lógico-trancedental da sua validade e, como tal, não tem nenhum caráter ético, político, mas apenas um caráter teórico-gnoseológico." (KELSEN, 1998, 117).

9 There is a long tradition in religious and political thought praising this moment - the moment when 'unknowing' and deciding cross paths, when freedom and moral responsibility join hands. It is, I think, what Carl Schmitt had in mind by 'deciding on the exception', or what Max Weber spokes as having a 'vocation for politics'. It is what Kierkegaard spoke of as the 'man of faith' or what Sartre described as the exercise of responsible human freedom. It is I think, what Derrida meant by 'deconstruction'. The sudden experience of unknowing, with time marching forward to determination, action, decision - the moment when the deciding self feels itself thrust forward, unmoored, not the experience (KENNEDY, 2007, 644-645).
} 
acima da vontade dos Estados, tomados isoladamente. Depende do pertencimento a uma comunidade, na qual é possível o mútuo reconhecimento de subjetividades (jurídicas). Deste segundo momento conclui-se que a norma fundamental é uma norma pressuposta e que existe uma única ordem jurídica universal baseada na consciência de juridicidade e, por lógica, esta ordem está hierarquicamente acima das ordens constitucionais, pois a consciência na comunidade - referente à intersubjetividade - é um fator facultado não à declaração autônoma do Estado, mas ao reconhecimento intersubjetivo.

A eficiência para Kelsen nada mais é do que o reconhecimento de relações de poder que operam de fato, na realidade. Suas afirmações partem de dois pressupostos epistemológicos: o mundo é passível de ser descrito e este mundo é o mesmo que o observado por outros (homens), ainda que reconhecidamente existam diferentes percepções. Esta interpretação da norma fundamental só é possível a partir do estudo em conjunto das caracterizações psicológicas do Estado contidas na versão do 'Hauptprobleme der Staatsrechtslehre', de 1923, da noção da eficiência das relações de poder na primeira versão da Teoria Pura do Direito de 1934 e da mudança da teorização da norma fundamental do contexto hipotético para o ficcional nas versões da ‘Teoria Pura do Direito’ de 1960 e ‘Teoria Geral das Normas’ de 1979.

\section{Referências bibliográficas}

BINDSCHEDLER, R.L.. Zum Problem der Grundnorm. In: ST. VEROSTA, ZEMANEK, I. Seidl-Hohenveldern. Völkerrecht und Rechtliches Weltbild: Festschrift für Alfred Verdross. Wien: Springer Verlag, 1960.

BULYGIN, Eugenio. Das Problem der Geltung bei Kelsen. In: PAULSON, Stanley L.; STOLLEIS, Michael. Hans Kelsen: Staatsrechtslehrer und Rechtstheoretiker des 20. Jahrhunderts. Tübingen: Mohr Siebeck, 2005.

CORREAS, Óscar (compilador). El Otro Kelsen. Mexico: Universidade Nacional Autônoma de Mexico, 1989.

FRANCK, Thomas. The Power of legitimacy among nations. New York: Oxford University Press, 1990.

M.. Legitimacy in International System. In: The American Journal of International Law. Vol. 82, nr. 4, oct. 1988, pp. 705-759.

HART. H. L. A.. The concept of law (1961). Second edition. Oxford: Oxford University Press, 1994.

Post scriptum al concepto de derecho (1994). Mexico: Universidad Nacional 
Autonoma de Mexico, 2000.

KELSEN, Hans. Acerca de las fronteras entre el método juridico y el sociológico. (1911) In: CORREAS, Óscar (compilador). El Otro Kelsen. Mexico: Universidade Nacional Autônoma de Mexico, 1989.

. Teoria Geral do Direito e do Estado (1945). São Paulo: Martins Fontes, 2005.

Reine Rechtslehre: Einleitung in die rechtswissenschaftliche Problematik (1934). Studienausgabe der 1 Auflage 1934. Herausgegeben und eingeleitet von Matthias Jestaedt. Tübingen: Mohr Siebeck, 2008.

. General Theory of Law and State (1945). Third printing. Cambridge, Massachusetts: Harvard University Press, 1949.

. Théorie Pure du Droit: Introduction a la Science du Droit (1953). Traduit de l'allemand par Henri Thévenaz. Neuchatel (Suisse): Éditions de la Baconnière, 1953.

Teoria Pura do Direito (1960). 6. ed., Tradução de João Batista Machado. São Paulo: Martins Fontes, 1998.

Principles of International Law (1952). Eighth printing. New Jersey: The Lawbook Exchange, Ltd.., 2008.

O problema da Justiça (1960). São Paulo: Martins Fontes, 1998.

Allgemeine Theorie der Normen. Im Auftrag des Hans-Kelsen-Instituts aus dem Nachlassherausgegeben von Kurt Ringhofer und Robert Walter. Wien: Manzsche Verlags- und Universitätsbuchlandung, 1979.

KENNEDY, David. One. Two, Three, many legal orders: legal pluralism and the cosmopolitan dream. In: N.Y.U. Review of Law and Social Change. Nr. 657, Vol. 31:64. New York: New York University School of Law, 2007. pp. 641-659

LAFER, Celso (et al). José Guilherme Merquior, Diplomata. Brasília: Fundação Alexandre de Gusmão, 1993.

LEISNER, Anna. Kontinuität als Verfassungsprinzip: unter besonderer Berücksichtigung des Steuerrechts. Tübingen: Mohr Siebeck, 2002.

MERQUIOR, José Guilherme. O problema da Legitimidade em Política Internacional: Tese apresentada no I Curso de Altos Estudos do Instituto Rio Branco. In: LAFER, Celso (et al). José Guilherme Merquior, Diplomata. Brasília: Fundação Alexandre de Gusmão, 1993. (pp. 09-14)

MOREIRA, Felipe Kern. Direito e Legitimidade na Sociedade Internacional. Boa Vista: Editora da UFRR, 2010.

SCHMITT, Carl. Völkerrechtliche Grossordnung mit Interventionsverbot für raumfrende Mächte: Ein Beitrag zum Reichsbegriff im Völkerrecht (1941). Berlin: Duncker \& Humblot, 1991.

TEUBNER, Gunter. Alienating justice: on the surplus value of the twelfth camel. In: 
NELKEN, David; PRIBÁN, Jirí (eds.). Lawe's New Boundaries: Consequences of Legal Autopoiesis. Ashgate: Aldershot, 2001. pp. 21-44.

VAIHINGER, Hans. Die Philosophie des Als Ob: System der theoretischen, praktischen und religiösen Fiktionen der Menschheit auf Grund eines idealistischen Positivismus. Neudruck der 9. 10. Auflage Leipzig 1927.

VERDROSS, Alfred. Völkerrecht. Vierte Neubearbeite und Erweiterte Auflage. Viena: Springer - Verlag, 1959.

VINX, Lars. Hans Kelsen's Pure Theory of Law: Legality and Legitimacy. Oxford: Oxford University Press, 2007. 